\title{
EEG-Related Changes to Fatigue during Intense Exercise in the Heat in Sedentary Women
}

\author{
Asma Kacem1 ${ }^{1}$, Foued Ftaiti ${ }^{1,2}{ }^{*}$, Karim Chamari ${ }^{3}$, Mohamed Dogui ${ }^{4}$, Laurent Grélot ${ }^{5}$, \\ Zouhair Tabka ${ }^{1}$ \\ ${ }^{1}$ Department of Physiology and Functional Explorations, IBN EL JAZZAR Medicine Faculty, Sousse, Tunisia \\ ${ }^{2}$ Research Unit "Psycho-Cultural and Biological Determinants of the High Performance in Young People", Sport \\ High School, Sfax, Tunisia \\ ${ }^{3}$ Research Unit "Evaluation, Sport, Health", National Centre of Medicine and Science in Sport, Tunis, Tunisia \\ ${ }^{4}$ Department of Physio-Neurology, University Hospital of Sahloul, Sousse, Tunisia \\ ${ }^{5}$ Institute of Movement Sciences, Faculty of Sport Sciences, University of Mediterranean, Marseille, France \\ Email: ${ }^{*}$ ftaiti foued@yahoo.fr
}

Received 3 April 2014; revised 8 May 2014; accepted 16 May 2014

Copyright (C) 2014 by authors and Scientific Research Publishing Inc.

This work is licensed under the Creative Commons Attribution International License (CC BY).

http://creativecommons.org/licenses/by/4.0/

(c) (i) Open Access

\begin{abstract}
Purpose: This study examined the possible causal mechanisms of fatigue during intense exercise in the heat in a group of nine sedentary women. Methods: Two strenuous cycling sessions were performed, at $100 \%$ of maximal aerobic power, either in neutral $\left(\mathrm{N}-\mathrm{Ex}\right.$, air temperature: $22^{\circ} \mathrm{C} \pm$ $0.4^{\circ} \mathrm{C}$, air humidity: $53 \% \pm 8 \%$ ) or in heat conditions ( $\mathrm{H}-\mathrm{Ex}$, air temperature: $35^{\circ} \mathrm{C} \pm 0.3^{\circ} \mathrm{C}$, air humidity: $59 \pm 6$ ). Tympanic temperature (Tty), heart rate (HR), body mass loss (BML), lactate concentration [La] and brain electrical activity (EEG: $\alpha$ and $\beta$ waves and $\alpha / \beta$ ratio) were recorded. Results: Tty, HR and [La] increases $(p<0.001)$ did not differ significantly between conditions. However, Tty increase rate was significantly $(p<0.05)$ higher during H-Ex $\left(0.12 \pm 0.03^{\circ} \mathrm{C} \cdot \mathrm{min}^{-1}\right)$ than that during $\mathrm{N}$-Ex $\left(0.08 \pm 0.02^{\circ} \mathrm{C} \cdot \mathrm{min}^{-1}\right)$, and time to exhaustion (Time Limit at $100 \%$ ) was significantly $(p<0.01)$ decreased $(-18 \% \pm 4 \%)$ during H-Ex session. Under both conditions, $\beta$ waves decreased $(\mathrm{p}<0.05)$ and $\alpha / \beta$ ratio increased $(\mathrm{p}<0.05)$ significantly immediately before exhaustion. Conclusion: During exercise in the heat, the high rate of core temperature rising might be a critical factor triggering faster brain changes.
\end{abstract}

\section{Keywords}

Fatigue, Women, Brain, Intense Exercise, Hyperthermia

\footnotetext{
*Corresponding author.
}

How to cite this paper: Kacem, A., Ftaiti, F., Chamari, K., Dogui, M., Grélot, L. and Tabka, Z. (2014) EEG-Related Changes to Fatigue during Intense Exercise in the Heat in Sedentary Women. Health, 6, 1277-1285. 


\section{Introduction}

Fatigue should be acknowledged as an integrated complex phenomenon influenced by both psychological and physiological factors. Muscle fatigue, defined as an exercise-induced reduction in the ability of a muscle to generate force or power, may develop for a variety of reasons and involve both central and peripheral factors [1]. Even in well-motivated subjects, the relative importance of peripheral versus central factors (i.e. mechanisms acting at/or distally, or caudally to the neuromuscular junction, respectively) seems to vary markedly depending on the mode, intensity, and duration of the exercise [2] [3], besides the nutritional status of the subjects and the environmental conditions [3].

The fundamental differences between the morphotypes of the two genders have a considerable impact on their physical performances [4], poorer thermoregulation, and greater risk for heat injury [5]. They have a smaller inherent aerobic power and less muscular strength than man, reflecting physical size, body composition, hormonal status, and socio-cultural influences [4]. For sustained isometric maximal voluntary contractions of the elbow flexor muscles, Hunter et al. (2003) [6] reported that young women are less fatigable than young men for maxima, without any gender difference in the contribution of supraspinal fatigue mechanisms. This suggests that women exhibited lesser peripheral fatigue than men. In contrast, Russ and Kent-Braun (2003) [7] using a similar protocol showed greater central fatigue in men compared with women. Furthermore, studies that focused on peripheral physiological mechanisms showed that women present typically greater muscle endurance (less fatigability) than men [7]-[9], even if no differences can be found in other studies [6]. Most of these studies have focused on peripheral physiological mechanisms, mainly those within the muscle, to explain fatigue in women. Although a varying work-to-rest ratio does not seem to influence the extent of central fatigue [10], longer task duration [11] mostly with no rest periods [12] can lead to more central fatigue. In this line, Yoon et al. (2007) [13] clamed that the low-force task induced greater central fatigue than the high-force contraction did for both men and women.

As recently stated by Nybo (2010) [14], exercise with superimposed hyperthermia is a challenge to the brain, and also provides an excellent model for studying factors of importance for central fatigue. Hence, the aim of the present investigation was to determine the effect of intense exhaustive muscular exercise in sedentary women performed with and without heat stress on EEG responses.

We hypothesize that during exercise in the heat, the high rate of rise of core temperature might be a critical factor inducing faster brain changes.

\section{Methods}

\subsection{Subjects}

Nine healthy volunteer females participated in this study. They were informed of the nature and possible inconveniences associated with the experiment. Written informed consent was obtained from all subjects prior to participation. Ethical approval was obtained from the appropriate research ethics committee (Committee for Human Protection in Biomedical Research of Sousse-Tunisia) and therefore the study was performed in accordance with the ethical standards laid down in the 1964 Declaration of Helsinki. Their mean age and body mass, \% of body fat, height and $\mathrm{VO}_{2} \max$ were $23 \pm 1 \mathrm{yr}, 63 \pm 4 \mathrm{~kg}, 19.9 \% \pm 3 \%, 1.72 \pm 0.04 \mathrm{~m}$ and $35 \pm 4 \mathrm{ml} \cdot \mathrm{min}^{-1} \cdot \mathrm{kg}^{-1}$, respectively. All women were tested in the middle of the follicular phase (FP) of the menstrual cycle between the 2nd and the 9th days after the menstruation phase. They are no smokers and they did not take any medication or nutritional supplements during all the testing sessions' period. They were asked to refrain from physical activities for $24 \mathrm{~h}$ before every test, and to avoid coffee, and cigarettes consumption during the testing days. Diet was controlled prior testing.

\subsection{Preliminary Testing}

One week before the cycling sessions, subjects completed a preliminary trial to determine body composition and maximal aerobic power. Skin-fold thickness was measured at four sites: triceps, suprailiac, abdomen and thigh [15] using a calliper (Harpenden, France). The percentage of body fat was calculated according to Durnin and Womersley (1974) [16].

Maximal aerobic power was determined for each subject during a progressive and maximal exercise on ergocycle (Ergoline, Germany). Increasing load was performed according to a standardized and individualised pro- 
tocol (Wasserman, 1987) [17]. This session started by a warm-up period of 3 min at $20 \%$ of the previously determined theoretical maximal aerobic power (TMAP). This was followed by power increments every minute until exhaustion. Power increment was about $8 \%$ of the TMAP [17]. This allowed the determination of both $\mathrm{VO}_{2}$ max and maximal aerobic power, based on the usual criteria for $\mathrm{VO}_{2}$ max measurement i.e. a levelling-off in oxygen consumption, a respiratory exchange ratio exceeding 1.1, and an expected maximal heart rate value. The maximal aerobic power was taken as the cycling power at which $\mathrm{VO}_{2}$ max occurred. The subjects' ventilation (VE) and fractional concentrations of expired $\mathrm{O}_{2}$ and $\mathrm{CO}_{2}\left(\mathrm{FEO}_{2}\right.$ and $\left.\mathrm{FECO}_{2}\right)$ were measured continuously by a gas analyser (ZAN 600 Me $\beta$ greräte, Germany).

\subsection{Experimental Design}

The experimental protocol included 2 cycling sessions performed at similar times in the morning on different days (9.00 a.m.) either in neutral (N-Ex) or in heat (H-Ex) conditions. During all sessions, subjects benefited from continuous medical assistance, particularly involving checking of internal body temperature and blood pressure.

Each cycling session started by a warm-up period of $5 \mathrm{~min}$ at $40 \%$ of the previously determined maximal aerobic power. This was followed by cycling at $100 \%$ of maximal aerobic power (MAP) until exhaustion. The exercise duration was defined as the limit time at $100 \%$ of the MAP (Tlim100\%). During one of the session, subjects performed the cycling exercise in a thermoneutral environment (N-Ex: ambient temperature of $22^{\circ} \mathrm{C} \pm$ $0.4^{\circ} \mathrm{C}$ and air humidity of $53 \% \pm 8 \%$ ). The second session was performed in heat condition ( $\mathrm{H}-\mathrm{Ex}: 35^{\circ} \mathrm{C} \pm 0.3^{\circ} \mathrm{C}$ and air humidity of $59 \% \pm 6 \%$ ). A period of one week separated the two sessions and the order of sessions was randomized.

Heart rate (HR), tympanic temperature (Tty), plasma electrolytes $\left(\mathrm{Na}^{+}, \mathrm{Cl}^{-}\right.$and $\mathrm{K}^{+}$) concentrations and haematological parameters (hematocrit: Hct and haemoglobin concentration: [Hb]), lactate concentration, body mass loss (BML), electroencephalogram (EEG) and reaction time to a simple visual signal were measured during the cycling exercise. Heart rate (HR) was assessed via a cardio-frequency-meter (Polar NV, Kempele, Finland). Body temperature was estimated from the tympanic temperature (Tty) immediately before and after the exercise using the same procedure described in Rasch and Cabanac (1993) [18] study. Tty was measured by a tympanic probe (T type thermocouple designed by INSERM, unit 103, Montpellier, France). This probe was placed in the external auditory canal of the right ear. A slight pain indicated a contact between the probe and the tympanic membrane [18]. Time constant and stabilisation of the probe were $0.15 \mathrm{~s}$ and $2-3 \mathrm{~s}$, respectively. A moss plug placed into the ear sealed the auditory canal. Before each cycling exercise, the probe was calibrated over a temperature range of $33^{\circ} \mathrm{C}$ to $41^{\circ} \mathrm{C}$ as monitored with an electronic thermometer.

Blood sampling was performed $3 \mathrm{~min}$ before and $3 \mathrm{~min}$ after each cycling exercise from the right cephalic vein. In the entire study, all blood samples were taken in a sitting position. Haematological parameters i.e. (Hb) and (Hct) were measured automatically by a specific electrode (CIBA Corning 644, France) from a $3 \mathrm{ml}$ blood sample (in a NFS tube with an anti-coagulant K3 EDTA). Plasma concentrations of electrolytes $\left(\mathrm{Na}^{+}, \mathrm{K}^{+}\right.$, and $\mathrm{Cl}^{-}$) were measured automatically (YSI 1500 Sport, John Morris Scientific, Chatswood, Australia) and lactate concentrations were assessed using a whole-blood measuring device (L-Lactate Analyzer, Lactate Bayer, Sensor, France).

Body mass loss (BML) was determined from the pre- and post-exercise difference based on nude and dried body mass. Body mass was measured during all testing sessions using a force plate (Kistler $9290 \mathrm{C}$, Switzerland) with a $1 \mathrm{~g}$ accuracy.

\subsection{The Electroencephalogram Recording}

The EEG was continuously recorded throughout the cycling exercise over the prefrontal cortex [19] from a surface electrode. However, EEG was analysed during $90 \mathrm{~s}$ at rest, at the onset and the middle of the exercise, and immediately before exhaustion. To avoid movement artefacts, a reference electrode was placed arbitrary on the ear lobe level. EEG signals were amplified and sampled at a frequency of $500 \mathrm{~Hz}$ and data were analysed using a " $\triangle$ Med" EEG analyser (Coherence 3 NT, France). A power spectrum was calculated from the EEG signal using a fast Fourier transformation. The areas of the power spectrum in the $\alpha$-band $(8-13 \mathrm{~Hz})$ and $\beta$-band $(13-30$ $\mathrm{Hz}$ ) were quantified as $\alpha$ and $\beta$, respectively. Subsequently the $\alpha / \beta$ ratio was calculated. This ratio was used as an index of "fatigue" based on the rationale that a decrease in $\beta$ activity and an increase in $\alpha$ activity would reflect the decreased arousal or a decline in vigilance [1] [20] [21]. Also, all the $\alpha / \beta$ ratio was made relative to the 
value obtained during rest $(\alpha / \beta=100)$ before the exercise trial, eliminating trial-to-trial and person-to-person variations.

\subsection{Determination of the Simple Visual Reaction-Time}

Immediately before and after the cycling exercise, a simple reaction time to the appearance of a signal (blue colour square) on a Laptop screen, placed in front of the subject sitting on the ergo-cycle, was measured. The signal appeared 10 times; in randomized order with 300 to 500 ms in-between. Subject was asked to tick on the items displayed on the screen with the pc-mouse as quickly as possible in response to each signal. The best and the worst performances were suppressed from the analysed data to avoid the effect of chance or bad manipulation.

\subsection{Statistical Analysis}

Descriptive statistics were calculated for all data. Results are presented as means \pm standard deviation (SD). In order to compare the effect of "exercise" and "heat conditions" on Tty, HR, [Hb] and Ht changes a two way analysis of variance (ANOVA) with repeated measures was performed, taking into account the factors of preand post-exercise and heat sessions conditions. When significant main effects were found $(\mathrm{p} \leq 0.05)$ a post-hoc Scheffé multiple comparison test was applied to determine differences between conditions. BML, [La], Tty rate of rise and time to exhaustion (Tlim100\%) were compared with a one-way ANOVA with repeated measures (pre- and post-exercise). $\alpha$ and $\beta$ waves and the $\alpha / \beta$ ratio were analysed separately at rest, at the onset and the middle of the exercise, and immediately before exhaustion using two-way ANOVA (moment of EEG measurements, and heat condition) with repeated measures.

\section{Results}

\subsection{Tympanic Temperature, Heart Rate and Body Mass Changes}

Compared to the resting values, exercise induced a significant increase of Tty $(p<0.001)$ during N-Ex (mean gain $=+1.1^{\circ} \mathrm{C}$ ) and $\mathrm{H}$-Ex (mean gain $=+1.3^{\circ} \mathrm{C}$ ) sessions. Comparison of maximal Tty reached at the end of each session did not reveal any significant differences between conditions. However, Tty rate of rise was significantly $(\mathrm{p}<0.05)$ higher during H-Ex condition $\left(0.12 \pm 0.03^{\circ} \mathrm{C} \cdot \mathrm{min}^{-1}\right)$ than during $\mathrm{N}$-Ex condition $\left(0.08 \pm 0.02^{\circ} \mathrm{C} \cdot \mathrm{min}^{-1}\right)$ (Table 1).

Significant HR increase $(\mathrm{p}<0.001)$ was also noticed during N-Ex sessions (mean gain $=101$ beats $\cdot \mathrm{min}^{-1}$ ) and $\mathrm{H}$-Ex (mean gain $=100$ beats $\cdot \mathrm{min}^{-1}$ ). The HR increases did not differ significantly between conditions. However, rate of HR rise was significantly $(\mathrm{p}<0.05)$ greater during H-Ex condition $\left(9.3 \pm 2\right.$ beats $\left.\mathrm{min}^{-1}\right)$ than during N-Ex condition $\left(7.6 \pm 1\right.$ beats $\left.\cdot \mathrm{min}^{-1}\right)$ (Table 1$)$.

Body mass loss recorded at the end of the N-Ex and H-Ex sessions were $0.8 \% \pm 0.4 \%$ of BM and $1.1 \% \pm$ $0.2 \%$ of BM, respectively. Comparison did not reveal any significant differences between conditions (Table 1).

\subsection{Blood Lactate Concentration}

The analysis reveal a significant $(\mathrm{p}<0.001)$ increase in [La] during both N-Ex and H-Ex sessions. Furthermore, comparison of the maximal [La] recorded at the end of the cycling exercise did not show any significant difference between the two testing conditions (Table 1).

\subsection{Plasma Electrolytic and Haematological Parameters}

Table 2 presents mean values of the plasma electrolytic concentrations (sodium: $\mathrm{Na}^{+}$, potassium: $\mathrm{K}^{+}$, chloride: $\mathrm{Cl}^{-}$) and haematological parameters (Hct and [Hb]) recorded immediately before (pre) and after (post) N-Ex and H-Ex sessions, respectively. Comparison did not show any significant change of the pre-post exercise values for all electrolytic and haematological parameters in both sessions.

\subsection{The Exercise Duration (Tlim100\%)}

The H-Ex session was associated with a significant decrease $(\mathrm{p}<0.01)$ of the time to exhaustion (Tlim100\%: $-18 \% \pm 4 \%$ ) when compared to $\mathrm{N}-$ Ex session (11.1 \pm 1 min versus $13.5 \pm 2$ min respectively). 
Table 1. Mean values of the tympanic temperature (Tty), heart rate (HR), body mass and blood lactate concentration recorded immediately before (pre) and after (post) the exercise in thermoneutral (N-Ex) and heat (H-Ex) conditions. ${ }^{* * *}: \mathrm{p}<$ 0.001 (pre- post-significant differences).

\begin{tabular}{|c|c|c|c|c|c|c|c|c|}
\hline \multirow{2}{*}{$\begin{array}{l}\text { Parameters } \\
\text { Conditions }\end{array}$} & \multicolumn{2}{|c|}{$\operatorname{TTY}\left({ }^{\circ} \mathrm{C}\right)$} & \multicolumn{2}{|c|}{ HR (beats' $\min ^{-1}$ ) } & \multicolumn{2}{|c|}{ BM (Kg) } & \multicolumn{2}{|c|}{$\mathbf{L a}\left(\mathbf{m m o L} \cdot \mathbf{L}^{-1}\right)$} \\
\hline & Pre & Post & Pre & Post & Pre & Post & Pre & Post \\
\hline N-Ex & $37.1^{\circ} \pm 0.2^{\circ}$ & $38.2^{\circ} \pm 0.2^{\circ * * * *}$ & $83 \pm 7$ & $184 \pm 7^{* * *}$ & $62.8 \pm 4$ & $62.3 \pm 4$ & $1.4 \pm 0.4$ & $12.5 \pm 2^{* * *}$ \\
\hline H-Ex & $37.2^{\circ} \pm 0.2^{\circ}$ & $38.5 \pm 0.5^{* * *}$ & $\mathbf{8 6} \pm 7$ & $186 \pm 6^{* * *}$ & $62.9 \pm 4$ & $62.2 \pm 4$ & $1.6 \pm 0.8$ & $10.3 \pm 3^{* * *}$ \\
\hline
\end{tabular}

Table 2. Mean values of the plasma electrolytic $\left(\mathrm{Na}^{+}, \mathrm{K}^{+}, \mathrm{Cl}^{-}\right)$and haematological $(\mathrm{Ht}$, [Hb]) parameters recorded immediately before (pre) and after (post) the exercise in thermoneutral (N-Ex) and heat (H-Ex) conditions. Note that none of the parameters exhibit significant changes between the pre and post conditions in both N-Ex and H-Ex sessions.

\begin{tabular}{|c|c|c|c|c|c|c|c|c|c|c|}
\hline \multirow{2}{*}{$\begin{array}{l}\text { Parameters } \\
\text { Conditions }\end{array}$} & \multicolumn{2}{|c|}{$\mathrm{Na}^{+}\left(\mathbf{m m o L} \cdot \mathrm{L}^{-1}\right)$} & \multicolumn{2}{|c|}{$\mathrm{K}^{+}\left(\mathbf{m m o L} \cdot \mathbf{L}^{-1}\right)$} & \multicolumn{2}{|c|}{$\mathrm{Cl}^{-}\left(\mathrm{mmoL} \cdot \mathbf{L}^{-1}\right)$} & \multicolumn{2}{|c|}{ Ht (\%) } & \multicolumn{2}{|c|}{$[\mathbf{H b}]\left(\mathrm{g} \cdot \mathbf{d L}^{-1}\right)$} \\
\hline & Pre & Post & Pre & Post & Pre & Post & Pre & Post & Pre & Post \\
\hline N-Ex & $138.7 \pm 1.0$ & $141.0 \pm 2.0$ & $4.2 \pm 0.5$ & $4.1 \pm 0.5$ & $109.6 \pm 1.0$ & $110.4 \pm 2.0$ & $39.0 \pm 2.0$ & $41.0 \pm 2.0$ & $12.9 \pm 1.0$ & $13.7 \pm 2.0$ \\
\hline H-Ex & $138.9 \pm 2.0$ & $140.7 \pm 2.0$ & $3.9 \pm 0.3$ & $4.0 \pm 0.4$ & $106.9 \pm 2.0$ & $\mathbf{1 0 8 . 6} \pm 3.0$ & $38.7 \pm 2.0$ & $\mathbf{4 0 . 1} \pm 3.0$ & $\mathbf{1 2 . 7} \pm 1.0$ & $13.2 \pm 1.0$ \\
\hline
\end{tabular}

\subsection{The Simple Visual Reaction Time}

Results reveal a significant post exercise increase of this parameter only during the N-Ex session $(\mathrm{p}<0.01)$. No significant difference was revealed between the two conditions both before and after the exercise (N-Ex: from $371.3 \pm 72 \mathrm{~ms}$ to $417.8 \pm 92 \mathrm{~ms}$, mean gain $=46.5 \mathrm{~ms}$; H-Ex: from $375.2 \pm 64 \mathrm{~ms}$ to $381.4 \pm 63 \mathrm{~ms}$, mean gain $=$ $6.2 \mathrm{~ms})$.

\subsection{Electroencephalogram Variation (EEG)}

There was no difference in the EEG between trials at rest and during the exercise. The waves did not change significantly in both conditions during exercise. However, the $\beta$ waves increased significantly at the onset (OE) and the middle (ME) of exercise ( $\mathrm{p}<0.001)$ in N-Ex and H-Ex conditions, and decreased significantly $(\mathrm{p}<0.05)$ immediately before exhaustion (IBE) in both conditions (Table 3).

When compared to the resting values, the $\alpha / \beta$ ratio decreased significantly $(\mathrm{p}<0.001)$ in both trials throughout the exercise $(\mathrm{p}<0.001)$. However, when compared to the onset and to the middle of the exercise, this ratio was significantly increased ( $<0.01)$ during both N-Ex $(405 \% \pm 360 \%$ and $463 \% \pm 217 \%$, respectively) and H-Ex (365\% $\pm 313 \%$ and $463 \% \pm 366 \%$, respectively) trial (Figure 1).

\section{Discussion}

Exercise with superimposed hyperthermia is known to provide an excellent model for studying factors of importance for central fatigue [14]. Hence, to further investigate mechanisms underlying the central component of fatigue, we have built an experimental protocol combining an exhausting cycling exercise and heat stress. Most of the previous studies treating with central fatigue during exercise-induced hyperthermia experimented groups of trained males. However, central fatigue in untrained subjects especially females during intense exercise is not enough debated.

In the present study, the core temperature was estimated from the tympanic temperature (Tty). Newsham et al. (2002) [22] have demonstrated that rectal temperature changes are slower to detect core temperature changes compared to Tty. They also showed that, during exercise, the evolution of these latter is nearly the same. Sato et al. (1996) [23] showed that when a probe was successfully placed on the tympanic membrane, and the external canal was covered with cotton or a thermal insulating material, Tty was not affected by ambient temperature or by an alteration in skin temperature of the face or the head.

The main result of the present study was that intense exhaustive exercise either in neutral (N-Ex) or in heat (H-Ex) conditions alters brain electric activity in sedentary women. Thus, a significant decrease $(\mathrm{p}<0.001)$ of the $\alpha / \beta$ ratio was observed at the onset and the middle of the exercise followed by a significant $(\mathrm{p}<0.01)$ increase of this ratio immediately before exhaustion in both sessions. Furthermore, the H-Ex session did not in- 
Table 3. Variation of the $\alpha$ and $\beta$ waves recorded at rest (R), at the onset $(\mathrm{OE})$ and the middle (ME) of the exercise and immediately before exhaustion (IBE) during the 2 sessions. $\alpha$ and $\beta$ are presented in \% of the total EEG signal.

\begin{tabular}{lccc}
\hline & & $\boldsymbol{\alpha}$ Waves (\%) & $\boldsymbol{\beta}$ Waves (\%) \\
\hline \multirow{3}{*}{ N-Ex } & $\mathbf{R}$ & $7.1 \pm 2.3$ & $5.7 \pm 1.0$ \\
& OE & $3.4 \pm 1.1$ & $24.2 \pm 13.0$ \\
& ME & $3.1 \pm 1.0$ & $38.1 \pm 18.0$ \\
& IBE & $4.2 \pm 2.0$ & $14.0 \pm 14.0$ \\
H-Ex & $\mathbf{R}$ & $8.3 \pm 3.0$ & $6.1 \pm 1.6$ \\
& OE & $3.7 \pm 1.5$ & $27.4 \pm 13.5$ \\
& ME & $4.4 \pm 2.3$ & $41.2 \pm 15.2$ \\
& IBE & $5.7 \pm 2.9$ & $15.1 \pm 4.2$ \\
\hline
\end{tabular}

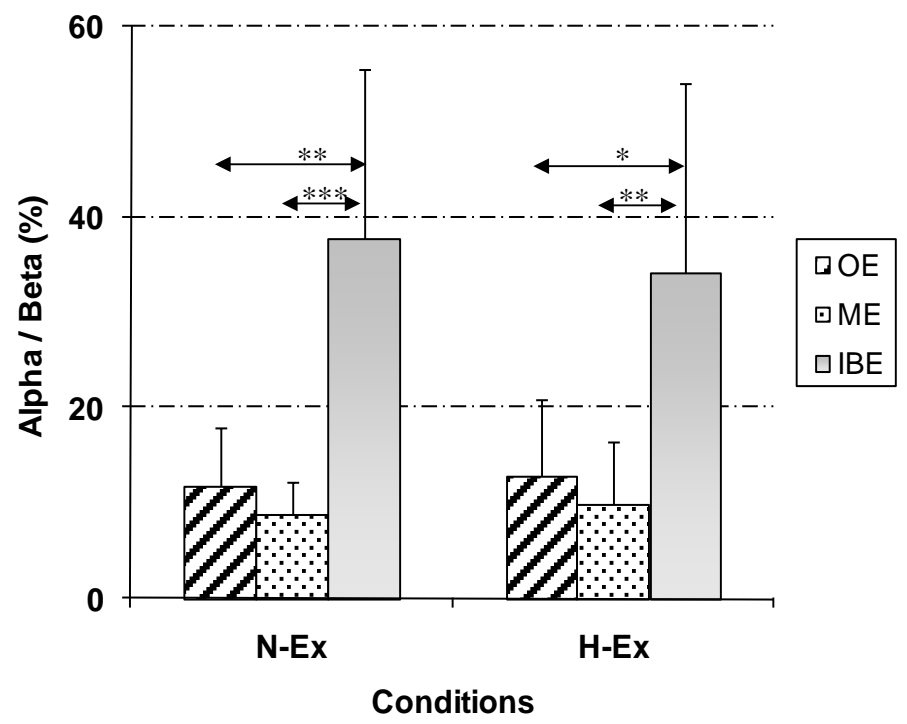

Figure 1. Variation of the $\alpha / \beta$ ratio according to the moment (R: rest, OE: onset of the exercise, ME: middle of the exercise and IBE: immediately before exhaustion) in the two conditions of tests. All the $\alpha / \beta$ ratio were presented according to the value obtained during rest $(\alpha / \beta=$ $100 \%$ ) before the exercise trial, eliminating trial-to-trial and person-to-person variation. (Asterisks $(*)$ indicate a significant difference between sessions at $\mathrm{p}<0.05$. Asterisks $(* *)$ indicate a significant difference between sessions at $\mathrm{p}<0.01$ ).

duce higher changes in Tty, HR, [La] and BML, while exercise duration was significantly decreased $(-18 \% \pm$ $4 \%, \mathrm{p}<0.01)$ compared to that of N-Ex session. This allowed suggesting that the higher rates of rise in both core temperature and HR $(\mathrm{p}<0.05)$ were the main factors allowing earlier exhaustion state during H-Ex session. In this line, Cheung and McLellan (1998) [24] reported that during severe uncompensable heat stress conditions, the rate of heat storage is the limiting factor for exercise-heat stress task. On the other hand, given the increase of the [La] during both N-Ex (from $1.4 \pm 0.4$ to $12.5 \pm 2 \mathrm{mmoL} \cdot \mathrm{L}^{-1}, \mathrm{p}<0.001$ ) and $\mathrm{H}$-Ex (from $1.6 \pm 0.8$ to 10.3 $\left.\pm 3 \mathrm{mmoL} \cdot \mathrm{L}^{-1}, \mathrm{p}<0.001\right)$ sessions, we can observe that contribution of the anaerobic glycolysis pathways for energy production was elevated. In such conditions, recent researches [25] [26] suggested that lactate has minimal involvement in the onset of muscle fatigue in such type of exercise. According to Robergs et al. (2004) [25], there is no biochemical support for lactate production causing intracellular acidosis. Even, if muscle did not produce lactate, acidosis and muscle fatigue would occur more quickly and exercise performance would be severely impaired [25]. Along with Philp et al. (2005) [27], explanation of fatigue certainly points to a combina- 
tion of effects, as opposed to one mechanism, causing fatigue, certainly in whole-organism function. Data of the present study does not support the idea that lactate accumulation and $\left[\mathrm{H}^{+}\right]$increase is the main cause of exhaustion during an intense cycling exercise. Indeed, the lower exercise duration observed in heat condition was accompanied by a lower absolute lactate concentration at the end of exercise $\left(10.3 \mathrm{mmoL} \cdot \mathrm{L}^{-1}\right.$ in $\mathrm{H}$-Ex vs. 12.5 $\mathrm{mmoL} \cdot \mathrm{L}^{-1}$ in N-Ex). It is likely that other causes than peak lactate were responsible for exhaustion.

When compared to the onset and the middle of the exercise, the $\alpha / \beta$ ratio was significantly increased $(\mathrm{p}<0.01)$ during both N-Ex and H-Ex trials (Figure 1). EEG results of the present study are not comparable to those reported by Nybo and Nielsen (2001) [1] and Nielsen et al. (2001) [20] underlining a relative stability of the $\alpha / \beta$ ratio during prolonged submaximal exercise, performed in thermoneutral condition, inducing a core temperature rise to $38^{\circ} \mathrm{C}$. However, during prolonged submaximal cycling exercise, Gonzalez-Alonso et al. (1999) [28] and Nybo and Nielsen (2001) [1] reported that exhaustion during prolonged exercise in the heat seems to coincide with the attainment of high internal temperatures close to $40^{\circ} \mathrm{C}$. In such condition, the core temperature increase did not only influence the locomotive and cardiovascular systems, but also affected the brain [2]. According to Ftaiti et al. (2010) [29], the $\alpha / \beta$ index increased significantly during submaximal prolonged and exhaustive cycling exercise particularly under heat condition. This was associated with a significant decrease of time to exhaustion (-34\%). During physical activities with intensities that elicit maximal oxygen uptake, Nybo (2008) [2] reported that lower performance is to a large extent related to peripheral fatigue. In contrast, during prolonged exercise in the heat, the decrease in endurance seems to involve changes in the function of the central nervous system (CNS) leading to a faster occurrence of fatigue. The CNS fatigue appears to be primarily related to inhibitory signals from the hypothalamus arising secondary to an increase in brain temperature [2]. In this line, Sidhu et al. (2008) [30] reported that supraspinal fatigue played a greater role than peripheral mechanisms in sustained maximal voluntary contraction reduction after locomotor exercise (eight 5 min bouts of cycling at 80\% of maximum workload).

The simple reaction time was not altered after the H-Ex session. The present results are in contradiction with those reported by Keller et al. (2004) [31] underlining in trained males the detrimental effect of heat stress on precision and concentration mental capacities. The results are also in disagreement with those reported by Ramsey et al. (1995) [32] showing that complex tasks are systematically altered during heat stress. On the other hand, our results are in agreement with the findings of Chmura et al. (1998) [33] who reported in trained males preservation or even an improvement of the treatment of the information capacity after $60 \mathrm{~min}$ of endurance cycling exercise in well trained subjects. In this line, Collardeau et al. (2001) [34] reported that CHO-electrolyte ingestion during a run resulted in an improvement in the complex cognitive performance measured at the end of 100 min treadmill run. Brisswalter et al. (2006) [35] indicated that when the cognitive performance was performed during exercise, the dual task effect was strongly related to energetic constraints of the task. The greater the energy demand, the more attention is used to control movements. However this positive effect disappears during prolonged exercise by an increase in errors in complex tasks and an alteration in perceptual response (i.e. the appearance of symptoms of central fatigue) [36]. According to Angevaren et al. (2008) [37], there is evidence that aerobic physical activities which improve cardiorespiratory fitness are beneficial for cognitive function in healthy older adults, with effects observed for motor function, cognitive speed, delayed memory functions and auditory and visual attention.

Studies relating changes in the EEG with vigilance have generally shown that deterioration in performance is associated with increased theta and changed alpha intensity [38], although Townsend and Johnson (1979) [39] have indicated that beta activity is also altered. These changes reflect decreased cortical arousal which is likely to occur during long monotonous tasks requiring sustained attention [40]. Belyavin and Wright (1987) [40] suggested that good and poor levels of vigilance can be predicted from the EEG changes. Performance was more closely related to the EEG in the simple vigilance task than with the discrimination task. The most useful discriminator of worsening vigilance common to both tasks was beta activity (14 - $21 \mathrm{~Hz})$ [40]. In the present study, although beta activity was significantly decreased in both conditions $(\mathrm{p}<0.001)$ results revealed a significant increase of the simple reaction time only after the N-Ex session.

\section{Conclusion}

This study revealed that exercise exhaustion in both neutral and a heat conditions is associated with changes in the spontaneous EEG, suggesting an alteration of the brain's neuronal activity, in sedentary women. Further- 
more, HR, Tty, BML and [La] concentration changes did not differ significantly between conditions, while time to exhaustion was significantly decreased during H-Ex session. In conclusion, a higher rate of core temperature increase in the heat seems to be the main factor leading to earlier stage of fatigue emergence in the heat.

\section{References}

[1] Nybo, L. and Nielsen, B. (2001) Perceived Exertion Is Associated with an Altered Electrical Activity of the Brain during Exercise with Progressive Hyperthermia. Journal of Applied Physiology, 91, 2017-2023.

[2] Nybo, L. (2008) Hyperthermia and Fatigue. Journal of Applied Physiology, 104, 871-878. http://dx.doi.org/10.1152/japplphysiol.00910.2007

[3] Reilly, T., Drust, B. and Gregson, W. (2006) Thermoregulation in Elite Athletes. Current in Opinion Clinical Nutrition and Metabolic Care, 9, 666-671. http://dx.doi.org/10.1097/01.mco.0000247475.95026.a5

[4] Shephard, R.J. (2000) Exercise and Training in Women: Influence of Gender on Exercise and Training Responses. Canadian Journal of Applied Physiology, 25, 19-34. http://dx.doi.org/10.1139/h00-002

[5] Bar-Or, O. (1998) Effect of Age and Gender on Sweating Pattern during Exercise. International Journal Sports Medicine, 19, S106-S107. http://dx.doi.org/10.1055/s-2007-971970

[6] Hunter, S.K., Critchlow, A., Shin, I.S. and Enoka, R.M. (2003) Fatigability of the Elbow Flexor Muscles for a Sustained Submaximal Contraction Is Similar in Men and Women Matched for Strength. Journal of Applied Physiology, 96, 195-202. http://dx.doi.org/10.1152/japplphysiol.00893.2003

[7] Russ, D.W. and Kent-Braun, J.A. (2003) Sex Differences in Human Skeletal Muscle Fatigue Are Eliminated under Ischemic Conditions. Journal of Applied Physiology, 94, 2414-2422.

[8] Clark, B.C., Collier, S.R., Minini, T.M. and Ploutz-Snyder, L.L. (2005) Sex Differences in Muscle Fatigability and Activation Patterns of the Human Quadriceps Femoris. European Journal Applied Physiology, 94, 196-206. http://dx.doi.org/10.1007/s00421-004-1293-0

[9] Hunter, S.K. and Enoka, R.M. (2001) Sex Differences in the Fatigability of Arm Muscles Depends on Absolute Force during Isometric Contractions. Journal of Applied Physiology, 91, 2686-2694.

[10] Taylor, J.L., Allen, G.M., Butler, J.E. and Gandevia, S.C. (2000) Supraspinal Fatigue during Intermittent Maximal Voluntary Contractions of the Human Elbow Flexors. Journal of Applied Physiology, 89, 305-313.

[11] Behm, D.G. and St-Pierre, D.M.M. (1997) Effects of Fatigue Duration and Muscle Type on Voluntary and Evoked Contractile Properties. Journal of Applied Physiology, 82, 1654-1661.

[12] Bilodeau, M. (2006) Central Fatigue in Continuous versus Intermittent Contractions of Triceps Brachii. Muscle Nerve, 34, 205-213. http://dx.doi.org/10.1002/mus.20572

[13] Yoon, T., Schlinder, D.B., Griffith, E.E. and Hunter, S.K. (2007) Mechanisms of Fatigue Differ after Low- and High-Force Fatiguing Contractions in Men and Women. Muscle Nerve, 36, 515-524. http://dx.doi.org/10.1002/mus.20844

[14] Nybo, L. (2010) CNS Fatigue Provoked by Prolonged Exercise in the Heat. Frontiers Bioscience, 2, 779-792. http://dx.doi.org/10.2741/e138

[15] Jackson, A.S. and Wilmore, J.H. (1978) Generalized Equations for Predicting Body Density in Men. British Medical Journal, 40, 499-504.

[16] Durnin, J.V.C. and Womersley, J. (1974) Body Fat Assessed from Total Body Density and Its Estimation from Skinfold Thickness: Measurements on 481 Men and Women Aged from 16 to 72 Years. British Journal of Nutrition, 32, 77-97. http://dx.doi.org/10.1079/BJN19740060

[17] Wasserman, K. (1987) Determinants and Detection of Anaerobic Threshold and Consequences of Exercise above It. Circulation, 76, V129-V139.

[18] Rasch, W. and Cabanac, M. (1993) Selective Brain Cooling Is Affected by Wearing Headgear during Exercise. Journal of Applied Physiology, 74, 1229-1233.

[19] Jasper, H. (1958) The Ten Twenty Electrode System of the International Federation. The International Federation of Clinical Neurophysiology. Electroencephalography and Clinical Neurophysiology, 10, 371-375.

[20] Nielsen, B., Hyldig, T., Bidstrup, F., Gonzalez-Alonso, J. and Christoffersen, G. (2001) Brain Activity and Fatigue during Prolonged Exercise in the Heat. Pflügers Archiv: European Journal of Physiology, 442, 41-48.

[21] Nielsen, B. and Nybo, L. (2003) Cerebral Changes during Exercise in the Heat. Sports Medicine, 33, 1-11. http://dx.doi.org/10.2165/00007256-200333010-00001

[22] Newsham, K.R., Saunders, J.E. and Nordin, E.S. (2002) Comparison of Rectal and Tympanic Thermometry during Exercise. Southern Medical Journal, 95, 804-810. 
[23] Sato, K.T., Kane, N.L., Soos, G., Gisolfi, C.V., Kondo, N. and Sato, K. (1996) Reexamination of Tympanic Membrane Temperature as a Core Temperature. Journal of Applied Physiology, 80, 1233-1239.

[24] Cheung, S.S. and McLellan, T.M. (1998) Influence of Short-Term Aerobic Training and Hydration Status on Tolerance during Uncompensable Heat Stress. European Journal Applied Physiology Occupational Physiology, 78, 50-58. http://dx.doi.org/10.1007/s004210050386

[25] Robergs, R.A., Ghiasvand, F. and Parker, D. (2004) Biochemistry of Exercise-Induced Metabolic Acidosis. American Journal of Physiology — Regulatory, Integrative and Comparative Physiology, 287, R502-R516. http://dx.doi.org/10.1152/ajpregu.00114.2004

[26] Westerblad, H., Allen, D.G. and Lännergren, J. (2002) Muscle Fatigue: Lactic Acid or Inorganic Phosphate the Major Cause? News in Physiological Sciences, 17, 17-21.

[27] Philp, A., Macdonald, A.L. and Watt, P.W. (2005) Lactate-A Signal Coordinating Cell and Systemic Function. Journal of Experimental Biology, 208, 4561-4575. http://dx.doi.org/10.1242/jeb.01961

[28] Gonzalez-Alonso, J., Teller, C., Andersen, S., Jensen, F., Hyldig, T. and Nielsen, B. (1999) Influence of Body Temperature on the Development of Fatigue during Prolonged Exercise in the Heat. Journal of Applied Physiology, 86, 10321039.

[29] Ftaiti, F., Kacem, A., Jaidane, N., Tabka, Z. and Dogui, M. (2010) Changes in EEG Activity before and after Exhaustive Exercise in Sedentary Women in Neutral and Hot Environments. Applied Ergonomics, 41, 806-811. http://dx.doi.org/10.1016/j.apergo.2010.01.008

[30] Sidhu, S.K., Bentley, D.J. and Carroll, T.J. (2008) Locomotor Exercise Induces Long-Lasting Impairments in the Capacity of the Human Motor Cortex to Voluntarily Activate Knee Extensor Muscles. Journal of Applied Physiology, 106, 556-565. http://dx.doi.org/10.1152/japplphysiol.90911.2008

[31] Keller, D., Blind, P., Keller, M., Pajot, P. and Bury, M. (2004) Exposition à un environnement chaud et performance en tir à la carabine. Science et Sport, 19, 48-50. http://dx.doi.org/10.1016/S0765-1597(03)00159-X

[32] Ramsey, J.D. (1995) Task Performance in Heat: A Review. Ergonomics, 38, 154-165. http://dx.doi.org/10.1080/00140139508925092

[33] Chmura, J., Krysztofiak, H., Ziemba, A.W., Kazar, K. and Kaciuba-Uścilko, H. (1998) Psychomotor Performance during Prolonged Exercise above and below the Blood Lactate Threes Hold. European Journal Applied Physiology and Occupational Physiology, 77, 77-80. http://dx.doi.org/10.1007/s004210050303

[34] Collardeau, M., Brisswalters, J., Vercruyssen, F., Audiffren, M. and Goubault, C. (2001) Single and Choice Reaction Time during Prolonged Exercise in Trained Subjects: Influence of Carbohydrate Availability. European Journal of Applied Physiology, 86, 150-156. http://dx.doi.org/10.1007/s004210100513

[35] Brisswalter, J., Collardeau, M. and René, A. (2002) Effects of Acute Physical Exercise Characteristics on Cognitive Performance. Sports Medicine, 32, 555-566. http://dx.doi.org/10.2165/00007256-200232090-00002

[36] Grego, F., Vallier, J.M., Collardeau, M., Rousseu, C., Cremieux, J. and Brisswalter, J. (2005) Influence of Exercise Duration and Hydration Status on Cognitive Function during Prolonged Cycling Exercise. International Journal of Sports Medicine, 26, 27-33. http://dx.doi.org/10.1055/s-2004-817915

[37] Angevaren, M., Aufdemkampe, G., Verhaar, H.J., Aleman, A. and Vanhees, L. (2008) Physical Activity and Enhanced Fitness to Improve Cognitive Function in Older People without Known Cognitive Impairment. Cochrane Database of Systematic Reviews, 16, Published Online.

[38] Gale, A., Davies, R. and Smallbone, A. (1977) EEG Correlates of Signal Rate Time in Task and Individual Differences in Reaction Time during a Five-Stage Sustained Attention Task. Ergonomics, 20, 363-376. http://dx.doi.org/10.1080/00140137708931639

[39] Townsend, R.E. and Johnson L.C. (1979) Relation of Frequency Analyzed EEG to Monitoring Behavior. Electroencephalography and Clinical Neurophysiology, 47, 272-279. http://dx.doi.org/10.1016/0013-4694(79)90279-7

[40] Belyavin, A. and Wright, N.A. (1987) Changes in Electrical Activity of the Brain with Vigilance. Electroencephalography and Clinical Neurophysiology, 66, 137-144. http://dx.doi.org/10.1016/0013-4694(87)90183-0 